\section{Cotton wool-like plaques due to Candida in ulcerative colitis}
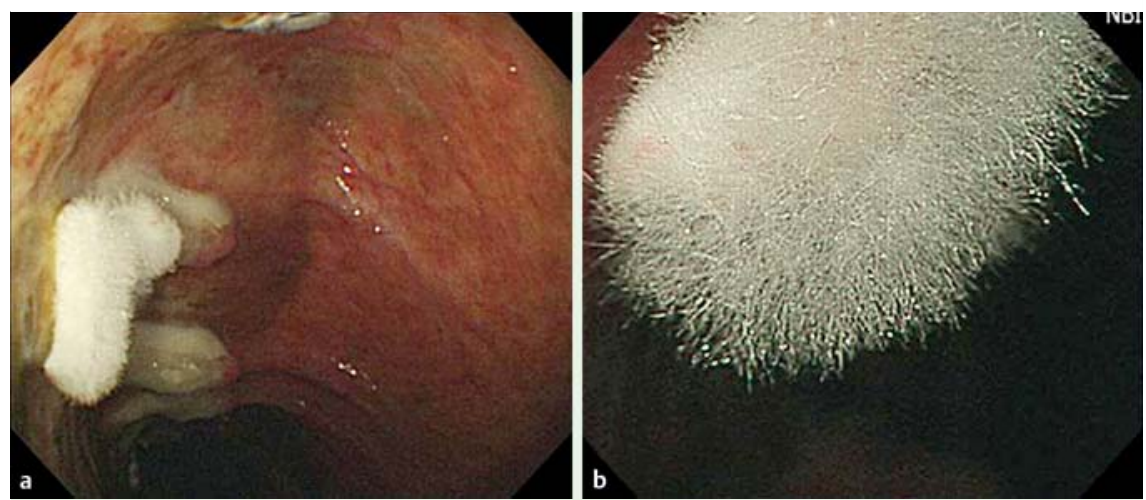

Fig. 1 A 62-year-old man with a long history of ulcerative colitis developed intermittent abdominal pain and prolonged diarrhea. After 5 weeks of treatment with prednisolone, he developed high fever and abdominal colic pain. a Colonoscopic imaging in the transverse colon revealed cotton wool-like plaques on a background of inflamed mucosa. $\mathbf{b}$ The lesions seemed to be an aggregation of filaments when magnified (under narrow-band imaging).

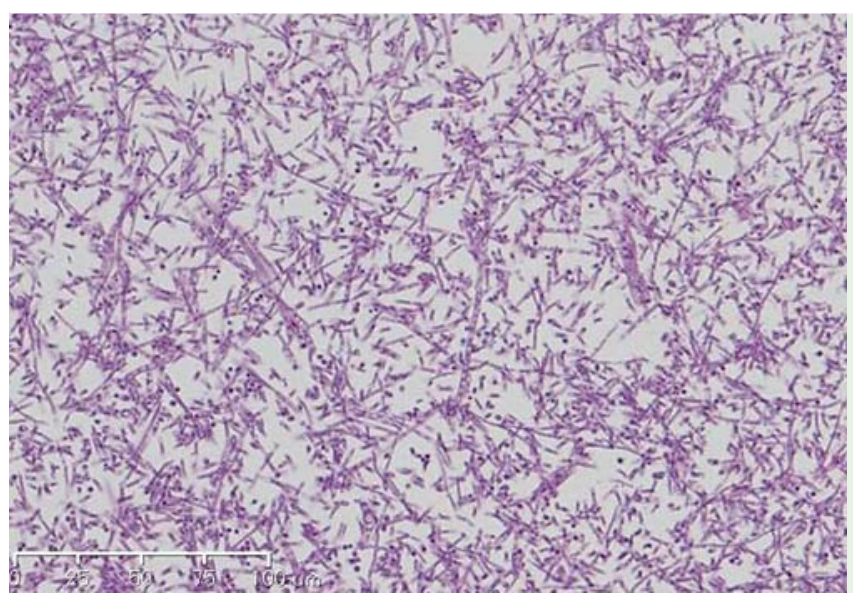

Fig. 2 On microscopic imaging, numerous Candida fungi were seen in the sample.

A 62-year-old man with a long history of ulcerative colitis and who was taking $2250 \mathrm{mg}$ of mesalazine and $50 \mathrm{mg}$ of azathioprine daily, developed intermittent abdominal pain and prolonged diarrhea. He was referred to our hospital with a suspicion of exacerbated ulcerative colitis. A physical examination revealed a man in acute distress with mild tenderness to palpation in the mid abdomen. Oral prednisolone was prescribed at a dose that was to be gradually decreased from $80 \mathrm{mg}$. After 5 weeks, when the dose of prednisolone had decreased to $30 \mathrm{mg}$, he developed high fever and abdominal colic pain. In his stool examination, Pseudomonas aeruginosa, Clostridium difficile, and some Candida species were present. Serum cytomegalovirus (CMV) antigen was also positive. Colonoscopy revealed multiple ulcers, marked granular change, and edema throughout the colon. White plaques as well as cotton wool-like plaques on a background of inflamed mucosa were seen in the transverse colon ( $\bullet$ Fig. 1 a). The lesions seemed to be an aggregation of filaments when magnified ( $\nabla$ Fig. $1 \mathbf{b}$ ). Samples were collected which led to the diagnosis of candidiasis ( $\bullet$ Fig. 2). Intravenous antifungal medication was administered, and the whitish plaques and inflammation disappeared within 2 months.

Acute infectious colitis mimics ulcerative colitis with the presence of diffuse lesions or focal colitis, thus necessitating differential diagnosis [1]. In ulcerative colitis, $C$. difficile and CMV infections are common while other infections such as Salmonella, Campylobacter, and Listeria monocytogenes have also have been reported [2,3]. There are some reports describing candidiasis of the digestive tract in immuno- compromised hosts [4], however, candidiasis in patients with ulcerative colitis has rarely been reported [5]. Patients with ulcerative colitis undergoing treatment with steroids or immunosuppressive agents, and who develop prolonged diarrhea or high fever, should undergo colonoscopy to evaluate whether this is due to a relapse of ulcerative colitis or to infection.

Endoscopy_UCTN_Code_CCL_1AD_2AZ

Competing interests: None

Yasuteru Fujino', Yoshifumi Takaoka', Naoki Muguruma', Miwako Kagawa', Toshiya Okahisa', Mika Sakaki², Tetsuji Takayama ${ }^{1}$

${ }^{1}$ Department of Gastroenterology and Oncology, The University of Tokushima Graduate School, Tokushima, Japan 2 Division of Pathology, Tokushima University Hospital, Tokushima, Japan

\section{References}

1 Rutgeerts $P$, Geboes $K$, Ponette $E$ et al. Acute infective colitis caused by endemic pathogens in western Europe: endoscopic features. Endoscopy 1982; 14: 212 - 219

2 Mylonaki M, Langmead L, Pantes A et al. Enteric infection in relapse of inflammatory bowel disease: importance of microbiological examination of stool. Eur J Gastroenterol Hepatol 2004; 16: 775-778

3 Kassalik M, Fry LC, Didowacz-Grollmann A et al. Listeria monocytogenes sepsis in ulcerative colitis. Endoscopy 2012; 44 (Suppl. 02): E219-220

4 Kumamoto CA. Inflammation and gastrointestinal Candida colonization. Curr Opin Microbiol 2011; 14: 386-391

5 Kudo T, Aoyagi Y, Fujii T et al. Development of Candida albicans colitis in a child undergoing steroid therapy for ulcerative colitis. J Pediatr Gastroenterol Nutr 2010; 51: 96 -99

\section{Bibliography}

DOI http://dx.doi.org/

10.1055/s-0034-1390841

Endoscopy 2015; 47: E61

(c) Georg Thieme Verlag KG

Stuttgart · New York

ISSN 0013-726X

\section{Corresponding author}

\section{Naoki Muguruma, MD, PhD}

Department of Gastroenterology and Oncology

The University of Tokushima Graduate School

3-18-15 Kuramoto-cho

Tokushima city 770-8503

Japan

Fax: +81-88-6339235

muguruma.clin.med@gmail.com 